\title{
Editorial
}

\section{Stress echocardiography: time for critical reappraisal}

Stress echocardiography combines cardiovascular stress with cross sectional echocardiography to detect ischaemia-induced wall motion abnormalities. It has been progressively developed for the evaluation of coronary artery disease since the first clinical description in 1979. ${ }^{1}$ Enthusiasm for the technique has grown for three reasons. First, echocardiography images myocardium, which makes it ideal for non-invasive assessment of global and regional ventricular function. Second, exercise electrocardiography has well-known limitations, including low sensitivity in single vessel disease, not infrequent false positives, equivocal results especially in patients with abnormal control ST segments, and unsuitability in those unable to exercise adequately. Last, low cost and freedom from radiation are important advantages of stress echocardiography.

Myocardial ischaemia is accompanied by characteristic mechanical, electrical, and perfusional abnormalities each of which has been used to detect coronary artery disease. The use of transient regional asynergy as a marker for ischaemia evolved after it was found that coronary artery ligation in animals produced a localised abnormality of myocardial contraction. ${ }^{2}$ Subsequent experimental $^{3}$ and clinical $^{4}$ studies confirmed that regional asynergy after the induction of ischaemia tends to precede electrocardiographic changes. This suggests that wall motion analysis may yield a more sensitive end point than ST segment shift.

The natural history of diagnostic tests is plagued by initial optimism and consequent reporting bias. Many do not withstand the test of time. So after 14 years of experience and with improvements in image quality, acquisition, and display what place is there for stress echocardiography in routine practice?

\section{Types of stress}

Exercise on a treadmill or supine or upright on a bicycle has been regarded as the preferred stress. ${ }^{5}$ Image acquisition at peak exercise is possible with bicycle ergometry and seems preferable to post-treadmill studies because rapid recovery of wall motion abnormalities may occur in up to $20 \%$ of cases. ${ }^{6}$ However, peak exercise imaging is technically difficult and obtaining images within one minute of treadmill exercise minimises the loss of sensitivity caused by rapid recovery. Rapid recovery may indicate a well developed collateral circulation whereas delayed recovery suggests multivessel disease. ${ }^{7}$

In patients unable to exercise to a sufficient workload, pharmacological or pacing stress is appropriate. ${ }^{8}$ Both intravenous dipyridamole (up to $1 \mathrm{mg} / \mathrm{kg}$ over $10 \mathrm{~min}$ utes) ${ }^{910}$ and adenosine (up to $\left.140 \mu \mathrm{g} / \mathrm{kg} / \mathrm{min}\right)^{11}$ are potent dilators of coronary resistance vessels and provoke ischaemia mainly by inducing flow redistribution. Since dipyridamole acts by potentiating endogenous adenosine, the effects of both can be reversed by aminophylline, an adenosine antagonist. Dobutamine predominantly stimulates $\beta_{1}$ adrenoceptors and induces ischaemia in patients with coronary artery disease by increasing the myocardial oxygen demand beyond the supply..$^{12}$ Infusion increments up to $20-30 \mu \mathrm{g} / \mathrm{kg} / \mathrm{min}$ are used and atropine is coadministered in any patient with an inadequate chronotropic response. ${ }^{12} 13$ Echocardiographic imaging during pharmacological stress has the advantage of being technically easier for the operator than exercise echocardiography because body and respiratory movements are absent. We found that dobutamine was a better tolerated and more effective stressor than dipyridamole, ${ }^{91012}$ an observation that has experimental support. ${ }^{14}$ Abrupt hypotension develops in about $15 \%$ of patients during the infusion. This reaction does not seem to be a marker for coronary artery disease ${ }^{15}$ but may be associated with the development of cavity obliteration and dynamic intraventricular "functional obstruction", 16 as has been observed in studies in dogs. ${ }^{17}$ When transthoracic imaging is poor, transoesophageal echocardiography with pacing stress is an option that, with the advent of omniplane probes, is no longer confined to imaging the transgastric short-axis view. ${ }^{18}$

\section{Image acquisition and analysis}

Real time digital image acquisition and display in a quad screen continuous loop format enables baseline and stress R-wave-triggered cine loops of the parasternal long axis, short axis, and apical four and two chamber views to be displayed side by side thereby considerably aiding interpretation. ${ }^{19}$ To eliminate respiratory artefact, images from four consecutive cardiac cycles are captured for each view and the best set is then selected for analysis. An informative image display is obtained by grabbing eight cells every $50 \mathrm{~ms}$ beginning on the $R$ wave with playback using $100 \mathrm{~ms}$ between cells. ${ }^{19}$ Commercially available systems allow easy storage, review, and analysis of images and are equipped with heart rate indicators and timers showing stress duration and post-stress image acquisition times. Image analysis is commonly performed by dividing the left ventricle into predefined segments and scoring each segment. ${ }^{20}$

A normal stress echocardiogram is defined by a uniform increase in wall motion and systolic wall thickening with a reduction in end systolic cavity area. An abnormal study conventionally encompasses baseline, new or worsening regional asynergy, tardokinesia or a failure to augment endocardial motion with stress. In our experience, patients with ventricular paced rhythm or a globally incoordinate left ventricular contraction pattern for other reasons have uninterpretable images and are therefore unsuitable for stress echocardiography. Some technical pitfalls causing falsely positive or negative examinations are recognised. Owing to oblique sectioning of the ventricle, apparent inferior asynergy on short axis imaging may occur in patients with low parasternal windows; normal motion of this wall in the two chamber view confirms its artefactual origin. Conversely, foreshortening of the left ventricle on apical imaging may lead to apical asynergy being overlooked. 
Training for stress echocardiography requires the performance of about 100 studies. After this, satisfactory images should be obtainable in about $90 \%$ of patients. ${ }^{21}$

\section{Clinical application}

Stress echocardiography has been used in the diagnosis of suspected coronary artery disease and to detect multivessl disease after myocardial infarction. ${ }^{5613}$ Test sensitivity depends on numerous factors including coronary reserve, potency of the stress, the extent of myocardium jeopardised, and imaging quality. Marwick et al studied 150 unselected patients and found that exercise echocardiography had a significantly higher sensitivity than exercise electrocardiography, both overall and for multivessel disease, and particular diagnostic value when ST segments were uninterpretable. ${ }^{22}$ Falsely negative studies correlated with submaximal stress, single vessel disease, and moderate (50-70\% diameter) coronary stenoses. ${ }^{22}$ In patients with normal wall motion at baseline, sensitivities and specificities of $87 \%$ and $86 \%$ for exercise echocardiography $^{22}$ and $89 \%$ and $85 \%$ for dobutamine echocardiography ${ }^{13}$ were reported. Most evidence supports a diagnostic role for stress echocardiography in patients with an intermediate pretest probability of coronary disease and an inconclusive exercise electrocardiogram. ${ }^{51222}$ Specificity is also improved because patients with a false positive exercise electrocardiogram such as women and patients with syndrome $\mathrm{X}$ commonly have normal regional systolic function on exercise echocardiography. ${ }^{23}$

Numerous studies describe the value of stress echocardiography for prognostic assessment in coronary artery disease, for risk stratification after uncomplicated myocardial infarction, and as a predictor of perioperative cardiac events. ${ }^{24-26}$ These preliminary reports are encouraging but not yet definitive largely because prognostic studies take time to complete. A normal exercise echocardiogram predicted good outcome in a study of 148 patients followed up for a mean of 28 months. ${ }^{27}$

Additional indications are assessment of the functional significance of coronary stenoses identified at angiography $^{28}$ and determination of the location and extent of inducible asynergy. As a rule separation of disease of the left anterior descending coronary artery from right coronary or circumflex disease is possible by relating the site of inducible asynergy to the coronary artery normally supplying that segment. ${ }^{12}$ The good temporal reproducibility of stress echocardiography makes it potentially suitable for serial application to monitor the effects of revascularisation or medical treatment. ${ }^{29}$ Recent reports describe its accuracy in detecting restenosis ${ }^{30}$ obstructed grafts, and progression of native disease ${ }^{3031}$ but these require confirmation, particularly because the confounding problem of abnormal septal motion after open heart surgery has been underemphasised. ${ }^{31}$

Stress echocardiography is appropriate where exercise electrocardiography is unlikely to provide a satisfactory answer to the clinical question being posed and should improve the selection of patients for tertiary referral. Similar evolutionary guidelines for clinical application have been proposed by a joint American College of Cardiology/American Heart Association task force ${ }^{32}$ and by investigators in the United States ${ }^{33}$ and Italy. ${ }^{34} \mathrm{We}$ advocate exercise echocardiography post-treadmill and believe that dobutamine will emerge as the best nonexercise stress. ${ }^{1012}$ Speed and convenience strengthen the economic arguments in favour of this technique whose reliability was emphasised early on by results that were highly concordant with gated blood pool imaging ${ }^{35}$ and more recently by comparison with single-photon emission computed tomography (SPECT) perfusion imaging. ${ }^{36}$

\section{Remaining issues}

Use of unrepresentative populations for test validation commonly leads to overestimation of the test's diagnostic accuracy. However, though inclusion of patients with non-atherosclerotic cardiac disorders usually decreases specificity, these cases are likely to be detected on baseline imaging, an important advantage of echocardiography. Another source of bias arises when only patients with positive studies are referred for coronary angiography, so increasing sensitivity and markedly decreasing specificity. The calculation of normalcy rates, using subjects unlikely to have coronary atheroma, addresses this problem..$^{22}$ The pretest likelihood of coronary artery disease in patients with symptoms may be estimated by probability analysis based on age, sex, and symptoms. ${ }^{37}$ When applied to stress echocardiography, the possibility that "probability analysis bias" may prejudice image interpretation is heightened by its subjective nature. Further improvements in image quality combined with progress in image enhancement techniques and automatic edge detection may make more objective, quantitative analysis of stress echocardiograms a practical proposition, though real problems are likely to remain. ${ }^{38}$

Worsening regional asynergy with stress, like ST segment shift on an abnormal baseline, may be an unreliable marker for ischaemia. ${ }^{39}$ The frequency with which nondiagnostic exercise electrocardiograms are associated with equivocal stress echocardiograms warrants further study. ${ }^{5}$ It is also possible that reductions in afterload with vasodilator stress may serve to mask new wall motion abnormalities. The extent to which traction from neighbouring healthy segments and regional unloading limit the ability of dobutamine echocardiography to identify viable myocardium after thrombolytic treatment for myocardial infarction also remains unclear. ${ }^{40}$ Finally, determination of the diagnostic accuracy of stress echocardiography by reference to an arbitrary angiographic definition of the severity of coronary stenosis is inadequate because this is not a physiological reference standard. ${ }^{41}$ The sensitivity and specificity of this test for detection of functionally significant single-vessel singlelesion coronary artery disease has still to be established. ${ }^{42}$

In conclusion, stress echocardiography is a useful adjunct for evaluation of coronary artery disease but it involves the purchase of new equipment and requires well trained personnel with enough time to perform the tests. Though further studies, including multicentre trials, are needed to clarify the remaining issues, the technique is now sufficiently validated to introduce into routine practice and should be more widely used. Its use to complement or replace exercise electrocardiography in selected patients, particularly for centres without easy access to nuclear imaging, should fall within the spectrum of facilities and expertise attainable in most hospitals.

PETER K MAZEIKA PETROS NIHOYANNOPOULOS CELIA M OAKLEY

Department of Medicine (Clinical Cardiology),

Royal Postgraduate Medical School, Hammersmith Hospital, Ducane Road, London, W12 ONN

PKM was formerly a CORDA research fellow. We thank CORDA for financial support.

1 Wann LS, Faris JV, Childress RH, Dillon JC, Weyman AE, Feigenbaum $H$. Exercise cross-sectional echocardiography in ischaemic heart disease. Circulation 1979;60:1300-8.

2 Tennant R, Wiggers CJ. The effect of coronary occlusion on myocardial contraction. Am $\mathcal{F}$ Physiol 1935;112:351-61. 
3 Battler A, Froelicher VF, Gallagher KP, Kemper WS, Ross J. Dissociation between regional myocardial dysfunction and ECG changes during ischemia in the conscious dog. Circulation 1980;62:735-44.

4 Sugishita Y, Koseki S, Matsuda M, Tamura T, Yamaguchi I, Ito I. Dissociation between regional myocardial dysfunction and ECG changes during myocardial ischaemia induced by exercise in patients

5 Armstrong WF, O'Donnell J, Dillon JC, McHenry PL, Morris SN, Feigenbaum $H$. Complementary value of two-dimensional exercise echocardiography to routine treadmill exercise testing. Ann Intern Med 1986;105:829-35.

6 Presti CF, Armstrong WF, Feigenbaum H. Comparison of echocardiography at peak exercise and after bicycle exercise in evaluation of patients with known or suspected coronary artery disease. $₹$ Am Soc Echocardiogr 1988;1:119-26.

7 Athanasopoulos G, Marsonis A, Joshi J, Oakley CM, Nihoyannopoulos P. Significance of delayed recovery after digital exercise echocardiography [abstract]. Br Heart $\mathcal{F}$ 1991;66:104-5.

8 Mazeika P, Nihoyannopoulos P, Nadazdin A, Oakley CM. Pharmacological stress echocardiography in the evaluation of coronary artery disease. Postgrad Med $₹$ 1991;67(suppl 1):S21-S35

9 Margonato A, Chierchia S, Cianflone D, Smith G, Crea F, Davies GJ et al. Limitations of dipyridamole-echocardiography in effort angina et al. Limitations of dipyridamole-ech

10 Mazeika P, Nihoyannopoulos P, Joshi J, Oakley CM. Uses and limitations of high dose dipyridamole stress echocardiography for evaluation of coronary artery disease. Br Heart $\mathcal{f}$ 1992;67:144-9

11 Zoghbi WA, Cheirif J, Kleiman NS, Verani MS, Trakhtenbroit A. Diagnosis of ischemic heart disease with adenosine echocardiography. $\Im$ Am Coll Cardiol 1991;18:1271-9.

12 Mazeika P, Nadazdin A, Oakley CM. Dobutamine stress echocardiography for detection and assessment of coronary artery disease. $7 \mathrm{Am}$ Coll Cardiol 1992;19:1203-11.

13 Sawada SG, Segar DS, Ryan T, Brown SE, Dohan AM, Williams R, et al. Echocardiographic detection of coronary artery disease during dobutamine infusion Circulation 1991:83:1605-14.

14 Fung AY, Gallagher KP, Buda AJ. The physiologic basis of dobutamine as compared with dipyridamole stress interventions in the assessment of as compared with dipyridamole stress interventions in

15 Mazeika P, Nadazdin A, Oakley CM. Clinical significance of abrupt vasodepression during dobutamine stress echocardiography. $\mathrm{Am} \mathcal{F}$ Cardiol 1992;69:1484-6.

16 Pellikka PA, Oh JK, Bailey KR, Nichols BA, Monahan KH, Tajik AJ. Dynamic intraventricular obstruction during dobutamine stress echocardiography. A new observation. Circulation 1992;86:1429-32.

17 White RI, Criley JM, Lewis KB, Ross RS. Experimental production of intracavitary pressure differences. Am $\mathcal{F}$ Cardiol 1967;19:806-17.

18 Lambertz H, Kreis A, Trumper H, Hanrath P. Simultaneous transesophageal atrial pacing and transesophageal two-dimensional echocardiography: a new method of stress echocardiography. $7 \mathrm{Am}$ Coll Cardiol 1990;16:1143-53.

19 Feigenbaum H. Digital recording, display and storage of echocardiograms. $\mathcal{F}$ Am Soc Echocardiogr 1988;1:378-83.

20 American Society of Echocardiography Committee on Standards, Subcommittee on Ouantitation of Two-Dimensional Echocardiograms. Recommendations for quantitation of the left ventricle by two-dimensional echocardiography. $¥ \mathrm{Am}$ Soc Echocardiogr 1989;2:358-67.

21 Picano E, Lattanzi F, Orlandini A, Marini C, L'Abbate A. Stress echocardiography and the human factor: the importance of being expert. $\mathcal{A m}$ Coll Cardiol 1991;17:666-9.

22 Marwick TH, Nemec JJ, Pashkow FJ, Stewart WJ, Salcedo EE. Accuracy and limitations of exercise echocardiography in a routine clinical setting. $\Im$ Am Coll Cardiol 1992;19:74-81.

23 Nihoyannopoulos P, Kaski JC, Crake T, Maseri A. Absence of myocardial dysfunction during stress in patients with syndrome X. $7 \mathrm{Am}$ Coll
Cardiol 1991;18:1463-70.

24 Picano E, Severi S, Michelassi C, Lattanzi F, Masini M, Orsini E, et al. Prognostic importance of dipyridamole-echocardiography test in coronary artery disease Circulation 1989:80:450-57.

25 Ryan T, Armstrong WF, O'Donnell JA, Feigenbaum H. Risk stratification after acute myocardial infarction by means of exercise two-dimensional echocardiography. Am Heart $\mathcal{F}$ 1987;114:1305-16.

26 Mazeika P, Nadazdin A, Oakley CM. Prognostic value of dobutamine echocardiography in patients with high pretest likelihood of coronary artery disease [abstract]. Br Heart f 1992;68:123.

27 Sawada SG, Ryan T, Conley MJ, Corya BC, Feigenbaum H, Armstrong WF. Prognostic value of a normal exercise echocardiogram. Am Heart $f$ 1990;120:49-55.

28 Sheikh KH, Bengtson JR, Helmy S, Juarez C, Burgess R, Bashore TM, et al. Relation of quantitative coronary lesion measurements to the development of exercise-induced ischemia assessed by exercise echocardiography. $₹ \mathrm{Am}$ Coll Cardiol 1990;15:1043-51.

29 Oberman A, Fan PH, Nanda NC, Lee JY, Huster WJ, Sulentic JA, et al. Reproducibility of two-dimensional exercise echocardiography. $₹ \mathrm{Am}$ Coll Cardiol 1989;14:923-8.

30 Crouse LJ, Kramer PH. Exercise echocardiography. A book and videotape. 1st ed. Mount Kisco, New York: Futura, 1992:27-44.

31 Sawada SG, Judson WE, Ryan T, Armstrong WF, Feigenbaum H. Upright bicycle exercise echocardiography after coronary artery bypas grafting. Am $\mathcal{f}$ Cardiol 1989;64:1123-29.

32 A Report of the American College of Cardiology / American Hear Association Task Force on Assessment of Diagnostic and Therapeutic Cardiovascular Procedures (Subcommittee to Develop Guidelines fo the Clinical Application of Echocardiography). ACC/AHA guidelines for the clinical application of echocardiography. $7 \mathrm{Am}$ Coll Cardio 1990;16:1505-28.

33 Ryan T, Feigenbaum H. Exercise echocardiography. Am $\mathcal{f}$ Cardiol 1992;69(suppl H):82-9.

34 Picano E. Stress echocardiography. 1st ed. Berlin: Springer-Verlag, 1992:59-73.

35 Limacher MC, Quinones MA, Poliner LR, Nelson JG, Winters WL Waggoner AD. Detection of coronary artery disease with exercise twodimensional echocardiography. Description of a clinically applicable method and comparison with radionuclide ventriculography. Circulation 1983;67:1211-1218.

36 Quinones MA, Verani MS, Haichin RM, Mahmarian J, Suarez J, Zoghbi WA. Exercise echocardiography versus 201-thallium single-photon emission computed tomography in evaluation of coronary artery disease. Analysis of 292 patients. Circulation 1992;85:1026-31.

37 Diamond GA, Forrester JS. Analysis of probability as an aid in the clinica diagnosis of coronary artery disease. N Engl f Med 1979;300:1350-58

38 Force TL, Parisi AF. Quantitative methods for analyzing regional systolic function with two-dimensional echocardiography. In: Kerber RE, ed. Echocardiography in coronary artery disease. New York: Futura, 1988: 193-219.

39 Corday E, Hajduczki I, O'Byrne GT, Kar S, Areeda J, Corday SR. Echocardiographic criteria to distinguish reversible from irreversible myocardial ischaemia. Eur Heart 7 1988;9(suppl F):29-43.

40 Pierard LA, De Landsheere CM, Berthe C, Rigo P, Kulbertus HE. Identification of viable myocardium by echocardiography during dobutIdentification of viable myocardium by echocardiography during dobuttherapy: comparison with positron emission tomography. $\exists \mathrm{Am}$ Coll therapy: comparison with

41 White CW, W/right CB, Doty DB, Hiratza LF, Eastham CL, Harrison DG, et al. Does visual interpretation of the coronary arteriogram predict the physiologic importance of a coronary stenosis? $N$ Engl $7 \mathrm{Med}$ 1984;310:819-24.

42 Wilson RF, Marcus ML, Christensen BV, Talman C, White CW. Accuracy of exercise electrocardiography in detecting physiologically significant coronary arterial lesions. Circulation 1991;83:412-21. 